\title{
O PLANEJAMENTO DO SEU SISTEMA DE APRENDIZAGEM EMPRESARIAL: IDENTIFIQUE UMA VISÃO E AVALIE O SEU SISTEMA DE RELAÇÕES ${ }^{*}$
}
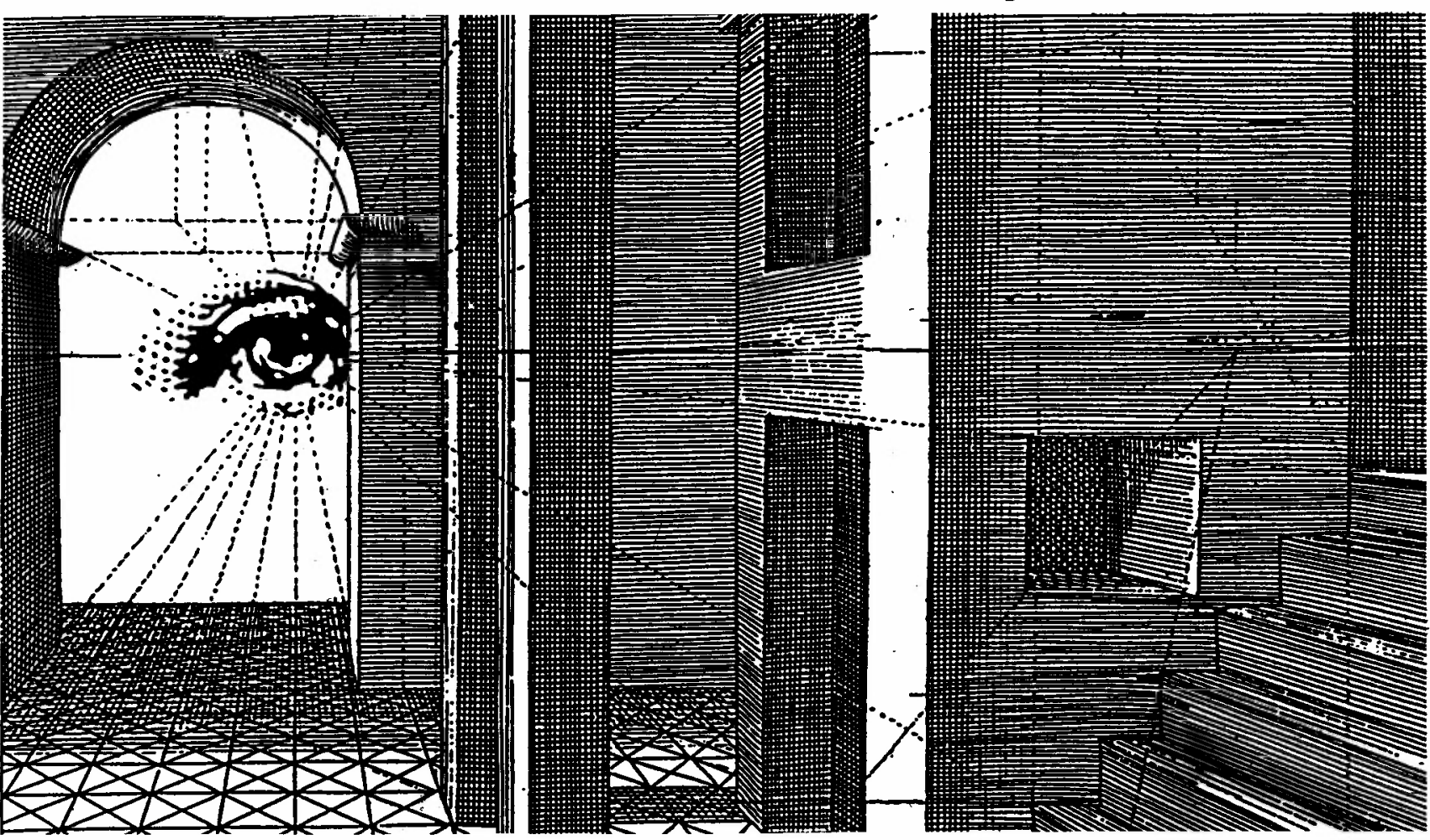

Louis Jacques Filion, PhD.

Professor do Departamento de Administração e Economia da Universidade de Québec em TroisRivières.

Tradução de Gledson Luiz Coutinho, professor do Departamento de Engenharia de Produção da Escola de Engenharia da UFMG.

* RESUMO: O autor se baseia em suas pesquisas e nas de outros estudiosos para propor um sistema de aprendizagem àqueles que se pretendem tornar empresários. O programa de aprendizagem somente poderá ser delineado a partir de uma visão que a pessoa consiga adquirir daquilo que ela pretenda ser e que a sua empresa seja. O principal fator de suporte tanto da criação como do desenvolvimento da visão $e ́$, aparentemente, o sistema de relações do empreendedor. Três outros fatores influem também no processo de formação da visão: a liderança, a energia e a percepção individual, esta condicionada pelos valores de cada um. Este último fator é designado pela palavra alemã Weltanschauung.
* PALAVRAS-CHAVE: Pequenas empresas, empreendedor, visão de negócio, sistemas de aprendizado.

* ABSTRACT: Based on his own and cited research, the author proposes a learning approach for working with people who want to become entrepreneurs. The basis is the identification of the "vision" the person has of personal and business goals. It is suggested that the principal factor in creating and developing this vision is the potential entrepreneurs system of "relations". Three other factors are also highlighted for their influence: leadership, energy and individual perception. The latter is seen as being condicioned by personal values and is given the German designation of "Weltanschauung".

* KEY WORDS: Small business, entrepreneurship, business vision, learning systems.

* Comunicação apresentada na "Terceira Conferência Canadense de Estudos Empresariais", Universidade de Calgary, 28 a 30 de setembro de 1989. 


\section{INTRODUÇÃO}

$\mathrm{P}$ esquisas anteriores identificaram o sistema de relações do empreendedor como sendo o elemento que melhor explica o desenvolvimento de sua visão ${ }^{1}$. Nas páginas que se seguem, serão apresentados, primeiramente, o enfoque baseado na visão do empreendimento e, em seguida, o modelo do sistema de relações que lhe serve de suporte $^{2}$. Por último, sugerem-se alguns exercícios capazes de colaborar para o desenvolvimento dessa visão e de proporcionar a cada empreendedor condições para planejar o seu próprio sistema ideal de relaçóes, considerada a visão em direção à qual ele pretende caminhar. Essas atividades são apresentadas como parte do sistema de aprendizagem do empreendedor.

\section{O PLANEJAMENTO DE UM SISTEMA DE APRENDIZAGEM DA ATIVIDADE EMPRESARIAL}

Neste texto, define-se empreendedor como alguém que concebe, desenvolve e realiza visões. Deve-se lembrar, também, que um empreendedor, usualmente, trabalha sozinho. Ele terá que aprender a ser diferente, se desejar ocupar e manter ocupado o nicho que tiver escolhido no mercado. Terá, ainda, que adquirir conhecimento ou, mais especificamente, conhecimento relacionado com o que ele deseja realizar. Collins e Moore ${ }^{3}$, assim como outros que vieram depois, observaram que muitos empreendedores têm saltado de um emprego para outro, aprendendo sobre

1. FILION, L.J. The Strategy of Successful Entrepreneurs in Small Business: vision, relations and Anticipatory learning. Tese de Doutorado, University of Lancaster (G.B), 1988.

2. FILION, L.J. "Le développment d'une vision: un outil stratégique à maitriser". Gestion, 14(3), set., 1989.

3. COLLINS, 0. \& MOORE, D.G. The Organization Makers: a behavioral study of independent entrepreneurs. New York, Appleton-Century-Crofts, 1970.

4. FILION, L.J. The Strategy of Successful Entrepreneurs in Small Business: vision, relations and anticipatory learning. Op. cit.

5. McLUHAN, Marshall. Understanding Media: the extensions of Man. Toronto, Signet Books, 1964.

\section{Figura 1: 0 processo de criação da visão}

produção acolá, e assim por diante. Essa ob servação leva à conclusão de que, na maior parte dos casos, a carreira do empreendedor se compõe de uma seqüência de empregos que lhe permite aprender o que ele considera necessário para implantar a sua própria empresa.

A forma de atuação do empreendedor é essencialmente proativa, já que ele identifica coisas novas que deverá aprender, tendo em vista as coisas novas que deseja realizar. De fato, quanto mais bem-sucedido ele for, mais se poderá imaginar que ele terá feito essa aprendizagem antecipada ${ }^{4}$.

A forma da aprendizagem parece ser tão importante quanto o que deve ser aprendido. Segundo Marshall McLuhan "o meio é a mensagem". No treinamento para as atividades empresariais, pode-se dizer que "o frasco" é mais importante do que o conteúdo. Para um empreendedor, a coisa mais importante é estar num processo dinâmico de aprendizagem, em que possa continuar a aprender indefinidamente. Ele continuará a aprender coisas que considerar interessantes ou que tenha identificado como necessárias para o seu objetivo. Assim, o planejamento do sistema de aprendizagem é uma tarefa que será melhor executada pelo próprio empreendedor, pois somente ele conhece as suas necessidades pessoais. A formulação e o desenvolvimento de uma visão facilitarão essa tarefa para ele.

\section{O PROCESSO DE CRIAÇÃO DA VISÃO: UM METAMODELO}

O termo metamodelo é empregado aqui no mesmo sentido em que foi usado por Stafford

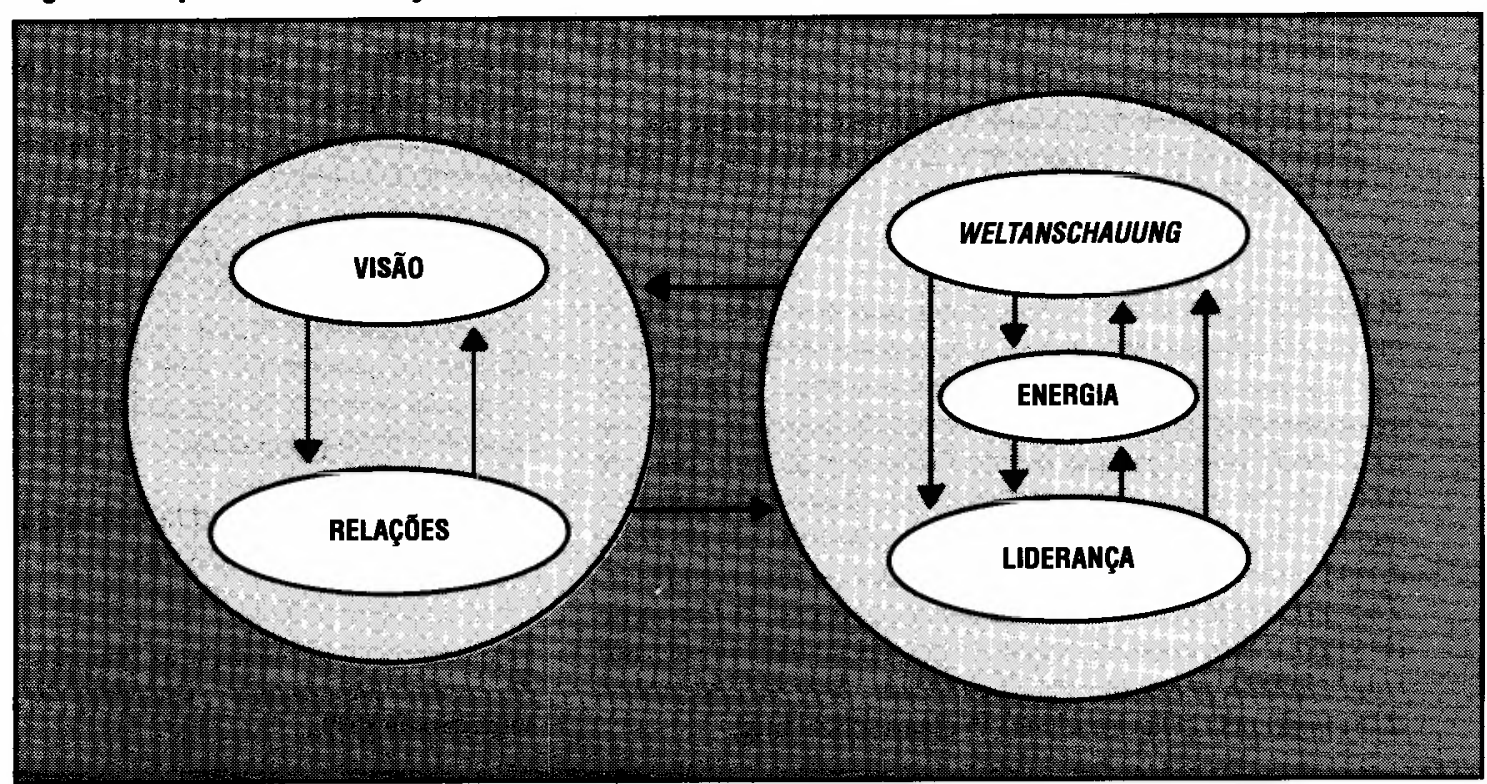


Beer e John P. Van Gigch 6 . Refere-se a um modelo com um certo nível de abstração, que integra as propriedades de modelos sistêmicos de nível inferior: neste caso, modelos sistêmicos de atividades humanas. Este metamodelo é a superposição de modelos revelados pelo estudo de empreendedores bemsucedidos ${ }^{7}$.

O modelo proposto incorpora quatro elementos de sustentação da visão, que se influenciam reciprocamente. Um deles, o sistema de relações, desempenha um papel mais importante e será discutido com maior profundidade, depois da apresentação sumária dos outros três.

\section{Weltanschauung ${ }^{8}$}

A Weltanschauung $(W)$ é a maneira pela qual o indivíduo vê o mundo real. Ela contém os valores, as atitudes, o humor $e$ as intenções subjacentes à percepção. Noutras palavras, é o que é percebido como significativo, quando a realidade que cerca a pessoa é vista através de filtros como as atitudes, os valores e as intenções. O termo está sempre associado a imagens, modelos e outras formas de representação da realidade. Assim como os valores, a Weltanschauung (W) não é definitiva, mas evolui continuamente, reformulada à luz do contexto em que o indivíduo opera ou pretende operar.

As Weltanschauungen (Ws) constituem a base sobre a qual se desenvolve o processo de estabelecimento da visão do empreendedor. Um processo que consiste, essencialmente, em projetar Ws sobre o futuro ou em escolher, imediatamente, as Ws ou as imagens que o empreendedor e a sua empresa vão perseguir no futuro. Evidentemente, é difícil para um empreendedor decidir se deseja ser alguma coisa, sem saber antes o que significa ser essa coisa. Portanto, um dos primeiros exercícios no processo de desenvolvimento da visão consiste em descrever os elementos que estão por trás das suas Ws ou imagens, isto é, por trás da sua maneira de perceber o mundo real. Isto o empreendedor pode fazer procurando entender a sua própria história, os valores e os modelos resultantes do seu passado familiar, a sua experiência profissional, sua educaçıo formal, sua educação informal (leitura, viagens, filmes etc.), suas crenças, seu sistema de relações etc.

\section{Energia}

Energia é o tempo alocado para atividades profissionais e a intensidade com que elas sao executadas. As $W_{s}$ ou valores do empreendedor vão certamente influenciar na definiçăo do que ele estará preparado para investir em sua vida profissional. A energia despendida pode conferir mais liderança, pode levar um empreendedor a dedicar mais tempo para criar e preservar relacionamentos ou para completar uma visão, e todas essas atividades reunidas podem resultar em alteração nas suas Ws. Além disso, a energia investida para assumir a liderança deverá ser devolvida ao empreendedor, pelo menos em parte, de uma forma ou outra, e, às vezes em quantidade maior do que ele investiu.

A energia despendida na criação e na manutenção de relacionamentos é compensadora, porque um empreendedor que esteja bem situado num sistema de relações beneficiar-se-á de um fluxo constante de informações, que lhe permitirá reajustamentos continuados. Também, quanto mais tempo e energia ele despender no desenvolvimento de sua visão, tanto mais benefício receberá, porque as diretrizes que ele desenvolver vão gerar motivação e energia naqueles que o cercam.

\section{Liderança}

A liderança resulta das $W s$, da energia e das relações, mas, reciprocamente, exerce influência sobre esses três elementos. Sua importância para o desenvolvimento da visão decorre do seu impacto sobre o nível da visão e da extensão daquilo que o empreendedor pretende realizar. A liderança afeta o seu desejo de realizar e isto, por sua vez, determina, em grande parte, até onde a sua visão alcança. $\mathrm{Na}$ realidade, é muito pouco provável que um líder vá além da sua visão, embora, como ocorre às Ws, ela seja parte de um processo contínuo, passível de reformulações periódicas.

A esta altura, podemos até mesmo questionar a origem da liderança: o que é que transforma uma pessoa em líder? Muita coisa pode ser mencionada, mas, no que tange aos empreendedores, a liderança parece surgir numa evolução gradual, que requer a aquisição de uma habilidade particular, num setor particular de atividade. A habilidade para desenvolver uma visão parece conferir liderança, e esta, para o empreendedor, parece depender do desenvolvimento da visão.

\section{Relações}

O sistema de relações, aparentemente, é o fator mais influente para explicar a evolução da visão. O sistema básico de relações de um empreendedor, a família, com certeza moldará os tipos de visão inicial que ele possa ter. Depois, as relações que ele estabelece, com a finalidade de desenvolver as suas visões secundárias, serão de importância fundamental
6. VAN GIGCH, John P.(Org.) Decision Making About Decision Making: metamodels and metasystems. Cambridge, Mass. e Tunbridge Wells, Kent (G.B), Abacus Press, 1987.

7. FILION, L.J. The Strategy of Successful Entrepreneurs in Small Business: vision, relations and anticipatory learning. Op. cit.

8. Weltanschauung. Esta palavra é da língua alemã, e o conceito tem sido usado, de há muito, por autores alemães, como, por exemplo, Max Weber. Peter Drucker ocasionalmente a emprega, assim como autores britânicos que têm participado do desenvolvimento de enfoques sistêmicos, como Boulding BOULDING, Kenneth E. The Image. Ann Arbour, University of Michigan Press, 1956. Não existe corresponde exato para esta palavra (em inglês), a mais próxima talvez seja "imagem". Kenneth Boulding examinou 0 conceito e suas implicações para aquele que toma decisões. *Nota da Editora: A tradução corrente de Weltanschauung no Brasil tem sido visão de mundo. 
para o desenvolvimento de sua visão central. Por outro lado, quanto mais articulada seja a sua visão, tanto mais importante será o papel por ela desempenhado na escolha dos critérios para o estabelecimento de um sistema de relações. O velho ditado "dize-me com quem tu andas $e$ eu te direi quem és" não poderia ser mais verdadeiro do que aqui. Para o enfoque baseado na visão, o ditado poderá até mesmo ser mudado para "dize-me quem tu queres que seja teu amigo e eu te direi quem tu serás".

$\mathrm{O}$ metamodelo proposto aqui é apenas um dentre os vários que incorporam os principais elementos dos modelos empregados por empreendedores bem-sucedidos. Ele representa o mais acessível denominador comum. Uma vez entendido, a pergunta que se faz é: como ele poderá ser usado para desenvolver uma visão, uma visão coerente? Nas páginas que se seguem, esta questão vai ser examinada.

\section{O desenvolvimento da visão}

$\mathrm{O}$ desenvolvimento de uma visão exige, desde o início, que certas condições sejam satisfeitas e certos passos sejam dados. As partes principais de um processo que se pode sugerir para isto serão apresentadas a seguir. As principais condições para que se realize o desenvolvimento da visão estão relacionadas no quadro 1.

O desenvolvimento e a subseqüente apresentação de uma visão pressupõem a existência de habilidade tanto de articulação como de comunicação. Para um empreendedor explicar a sua visão, terá que saber como persuadir e, logo, terá que possuir um bom conhecimento básico dos principais elementos envolvidos.

\section{TREINAMENTO DO EMPREENDEDOR}

O modelo pode ser usado também no treinamento do empreendedor.

O processo a ser seguido é o tema da parte restante deste trabalho.

\section{Identificação da visão}

O primeiro passo do empreendedor, para definir o que necessita aprender, deve ser no sentido de identificar e desenvolver uma visão daquilo que pretende realizar. Tal visão será uma referência tanto para as suas reflexões como para a sua ação. O quadro 2 sugere aos estudantes desse tema os passos para disparar esse processo.

No início, o estudante poderá julgar vantajoso trabalhar com apenas uma pessoa. Chegando ao último passo desse processo preliminar de desenvolvimento da visão, isto é, uma vez que tenha executado todos os passos preliminares do processo, sua visão começa a tomar forma.

Passos do processo de desenvolvimento da visão

Uma pergunta comum, a esta altura, referese à diferença entre visão, sonho e alucinação. A visão, naturalmente, inclui alguma intuição e, acima de tudo, imaginação; mas, ao contrário do sonho, ela diz respeito a ações reais a serem executadas. Aquele que possui uma visão, portanto, pode ser definido como um sonhador que deseja realizar um trabalho. De fato, os empreendedores que conseguiram desenvolver uma visão parecem tê-lo feito com auxílio de sua imaginação, sua reflexão e seu bom senso. Depois dos passos que cons-

\section{Quadro 1: Condições necessárias para o desenvolvimento de uma visão}

1. Canalizar as energias numa direção particular.

2. Concentrar-se num determinado campo de atividade e num determinado lugar.

3. Adquirir experiência e conhecimento no assunto.

4. Desenvolver, metodicamente, o pensamento vertical e o pensamento horizontal no campo de atividade em questão.

5. Capacidade de pensar e fazer escolhas.

6. Aptidão e desejo de se comunicar.

7. Inabalável determinação de realizar e concluir alguma coisa.

8. Perseverança para trabalhar por resultado a longo prazo. 
Quadro 2: Passos para iniciar o processo de desenvolvimento de uma visão

1. Avaliação de suas próprias áreas de interesse.

2. Avaliação de seus próprios pontos fortes e fracos.

3. Estimulação da imaginação pela leitura de estudo de casos biográficos.

4. Focalizaçāo de uma área de interesse que apresente efeitos sinérgicos com algum dos seus pontos fortes.

5. Desejo de iniciar o processo de desenvolvimento de uma visã́o.

tituem a fase preliminar, o desenvolvimento propriamente dito da visão se inicia. (Ver quadro 3.)

É verdade que a capacidade de articular uma visão requer a habilidade de conceber um ou mais cenários futuros. Os dois primeiros passos, o embriāo e o desenvolvimento, relacionam-se com visões iniciais. A decisão ou (série de decisões) a ser tomada no terceiro passo é uma peça-chave para formar uma visão central. Finalmente, o quarto passo exige que as visōes secundárias sejam utilizadas, se a visão central deve ser realizada.

Como se vê, em quase todos os passos, mas principalmente nos de números 2 e 3 , o processo requer a orientação por outras pessoas. $O$ instrutor pode desempenhar, ele mesmo, o papel de orientador ou pode pedir a cooperaçāo de empresários competentes, para isso. Cada aluno será designado para buscar orientação junto a um deles. Pode ser bastante útil oferecer a esses orientadores algumas diretrizes para o seu trabalho, sobretudo para que saibam o que é esperado deles.

$O$ treinamento para a atividade empresarial é similar, em muitos aspectos, ao treinamento para a liderança e, quando o treinamento está voltado para o desenvolvimento da visão, a similaridade é ainda maior. Autores interessados em pesquisa sobre liderança ou em treinamento e desenvolvimento de líderes têm observado o relacionamento pessoal, às vezes até afetivo, que surge entre o orientador e o seu orientado ${ }^{9}$. Diz-se, com frequiência, que Alexandre, o Grande, não teria sido Alexandre, o Grande, se não tivesse tido Aristóteles como seu orientador. $O$ progresso pessoal do estudante, no seu próprio ritmo e à sua maneira, fará com que ele se torne realmente envolvido no processo de aprendizagem. É bom lembrar que, numa parte inicial deste texto, foi dito com toda a clareza

Quadro 3: Passos do processo de desenvolvimento da visão

\begin{tabular}{|c|c|c|c|c|c|}
\hline Vúmero & Fase & Contaido & $\begin{array}{l}\text { Categoria } \\
\text { da visáo }\end{array}$ & $\begin{array}{l}\text { Aividade } \\
\text { exigida do } \\
\text { empreendedor. }\end{array}$ & $\begin{array}{l}\text { Ativitade } \\
\text { educacional } \\
\text { aidequatia }\end{array}$ \\
\hline 1 & Embrião & $\begin{array}{l}\text { Idéia do } \\
\text { produto } \\
\text { e/ou } \\
\text { serviço }\end{array}$ & Inicial & Imaginação & $\begin{array}{l}\text { Leitura de } \\
\text { biografias e estudos } \\
\text { das atividades de } \\
\text { empreendedores. }\end{array}$ \\
\hline 2 & $\begin{array}{l}\text { Desenvol- } \\
\text { vimento }\end{array}$ & $\begin{array}{l}\text { Estudos: } \\
\text { do mercado, } \\
\text { do produto, } \\
\text { de viabilidade. }\end{array}$ & Inicial & Reflexão & $\begin{array}{l}\text { Orientação por } \\
\text { outras pessaas. } \\
\text { Leituras sobre } \\
\text { administração. }\end{array}$ \\
\hline 3 & Forma & $\begin{array}{l}\text { Idéias de } \\
\text { empresa }\end{array}$ & Central & $\begin{array}{l}\text { Avaliação, } \\
\text { bom senso }\end{array}$ & $\begin{array}{l}\text { Orientação por } \\
\text { outras pessoas. } \\
\text { Estudos de casos, } \\
\text { discussão em grupo }\end{array}$ \\
\hline 4 & Alvo & $\begin{array}{l}\text { Objetivos } \\
\text { precisos } \\
\text { a serem } \\
\text { alcançados }\end{array}$ & Secundária & Concentração & $\begin{array}{l}\text { Conferências } \\
\text { Feedback }\end{array}$ \\
\hline
\end{tabular}

9. ZALEZNIK, A. "Managers and leaders: are they different?" Harvard Business Review,maio/junho, 1977, pp.6778; ZALEZNIK, A. The Managerial Mystique: restoring leadership in business. New York Harper and Row, 1989. 
que, no que tange à aprendizagem, do ponto de vista do empreendedor, "o frasco" parece ser mais importante do que o seu conteúdo e que deve ser permitido ao candidato a empreendedor estabelecer seu próprio método de aprendizagem, para que ele o possa continuar usando no futuro. O progresso na aprendizagem será mais fácil, se se fizer na linha da visão identificada. $O$ quadro 4 apresenta um exercício destinado a facilitar o desenvolvimento da visão.

\section{O Sistema de Relações}

O sistema de relações permanece como o elemento que, aparentemente, constitui o melhor suporte para o desenvolvimento da visão. As principais ligações entre o sistema de relações, as visões e as ações são apresentadas na figura 2.

Ali se vê que as relações condicionam as visões e as visões condicionam a escolha das relações. As relações e as visões dão origem
Figura 2: As ligações entre o sistema de relações, as visões $e$ as ações

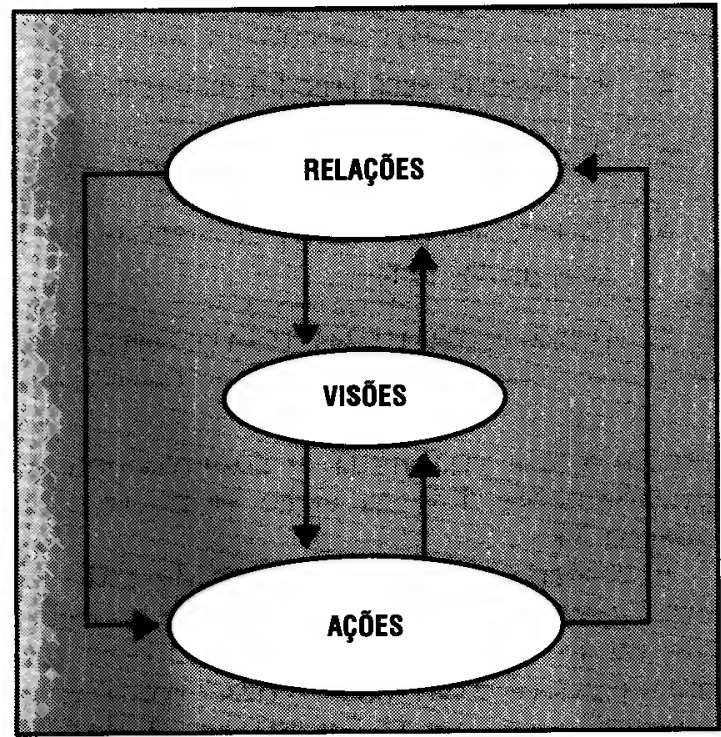

Quadro 4: Origem e desenvolvimento da visão - Exercício 1

1. Auto-avaliação:

- descrição das Ws-chave ("o que é importante e relevante para mim");

- energia;

- liderança;

- autoconceito;

- autonomia;

- exame dos pontos fortes e fracos.

2. Descrição dos modelos empresariais preferidos.

3. Identificação das áreas do mercado que oferecem oportunidades de negócio.

4. Descrição das visões iniciais.

5. Descrição de uma visão central.

Quadro 5: Os três níveis de relações

\begin{tabular}{|l|l|}
\hline \multirow{2}{*}{ PRIMÁRIO } & Familiares. \\
\cline { 2 - 2 } & Ligaçôes em torno de mais de uma atividade. \\
\hline \multirow{3}{*}{ SECUNDÁRIO } & Conhecidos. \\
\cline { 2 - 2 } & Ligação em torno de uma atividade bem determinada. \\
\cline { 2 - 2 } & Rede de ligações. \\
\hline \multirow{2}{*}{ TERCIÁRIO } & Cursos. \\
\cline { 2 - 2 } & Livros, viagens, feiras e exposiçôes industriais. \\
\hline
\end{tabular}


às ações; as ações requerem, freqüentemente, o estabelecimento de novas relações, que, por sua vez, influenciam o surgimento de novas visões.

Três níveis de relaçōes foram identificados e são apresentados no quadro 5. As relações primárias săo as que envolvem pessoas próximas do empreendedor, usualmente os membros de sua família, com quem ele mantém vínculos variados: afetivos, intelectuais, esportivos, recreativos etc. Essas relações são as mais influentes, no que dizem respeito às $W s$ básicas do empreendedor e às escolhas que, mais tarde, ele fará, noutros níveis, no sistema de relações.

À medida que o tempo passa, o empreendedor tenderá cada vez mais a desenvolver relaçōes secundárias e terciárias. As relaçōes secundárias desenvolvem-se a partir de atividades bem definidas: clubes sociais, grupos religiosos, negócios e política. Algumas acabam se transformando em relações primárias. As relações terciárias são escolhi- das para satisfazerem uma necessidade bem definida. Elas näo implicam, necessariamente, contato pessoal, mas apenas contato com a área de interesse.

A atenção dedicada ao gerenciamento dessas relações parece constituir um dos principais elementos que permitem ao empreendedor formar uma visão central coerente. Empreendedores que possuem uma visão e que contruiram sua empresa sempre dizem: "Para chegar onde queria, eu precisava aprender isso $e$ aquilo. $\dot{E}$ por isto que eu queria um emprego em tal empresa ou estudar em tal escola". Comentários assim ilustram uma forma típica de gerenciamento de relações terciárias, que geralmente conduzem ao desenvolvimento de relaçōes secundárias, ambas úteis e capazes de estimular o desenvolvimento da visâo.

Os três níveis de relacionamento, apresentados na figura 3 , assumem aspectos de três subsistemas: família, relacionamentos externos e relacionamentos internos à empresa.

Os fatores a serem administrados pelo em-

Figura 3: 0 sistema de relações

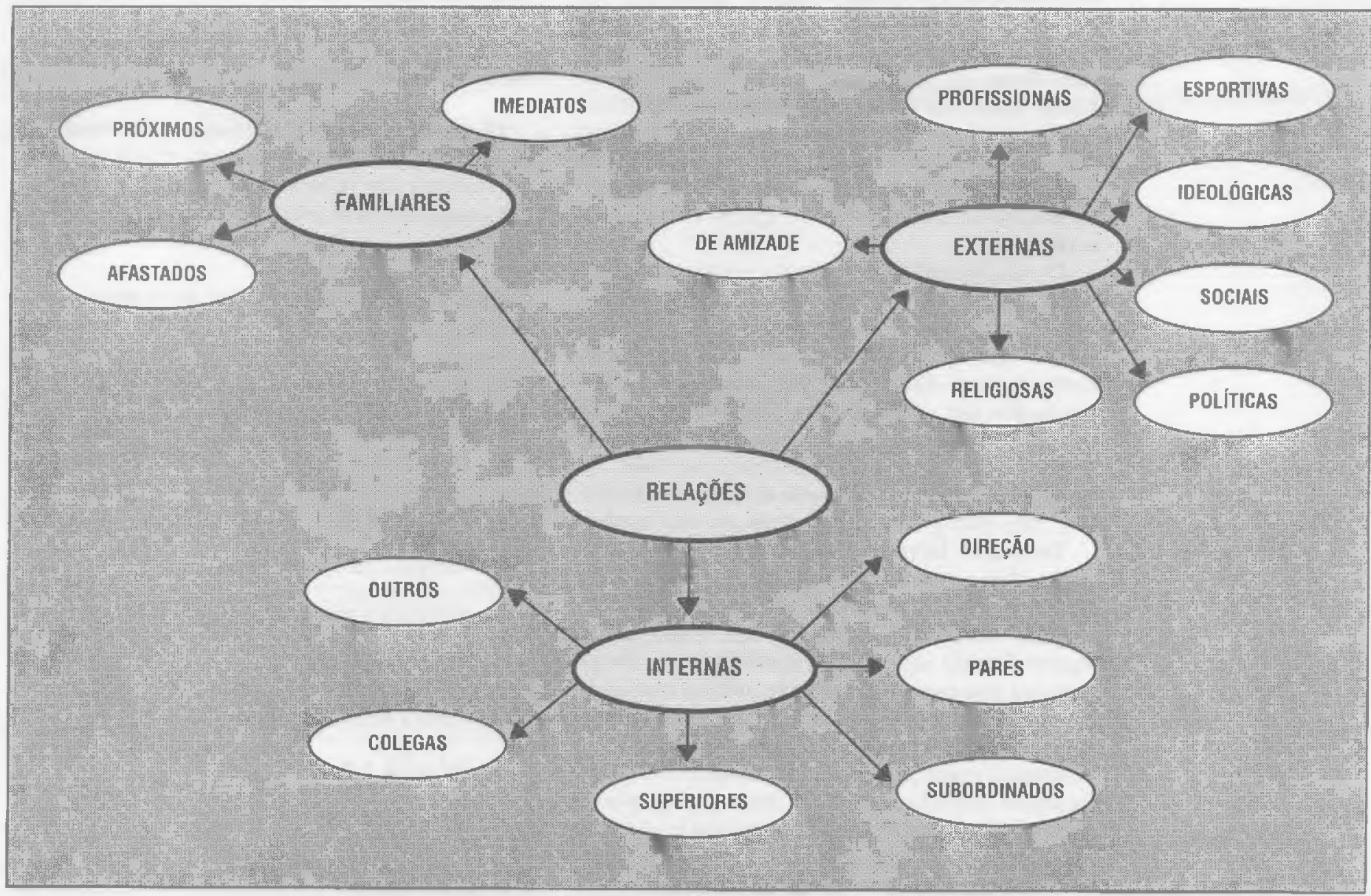


Flgura 4: 0 empreendedor $e$ as combinações visão $x$ relações

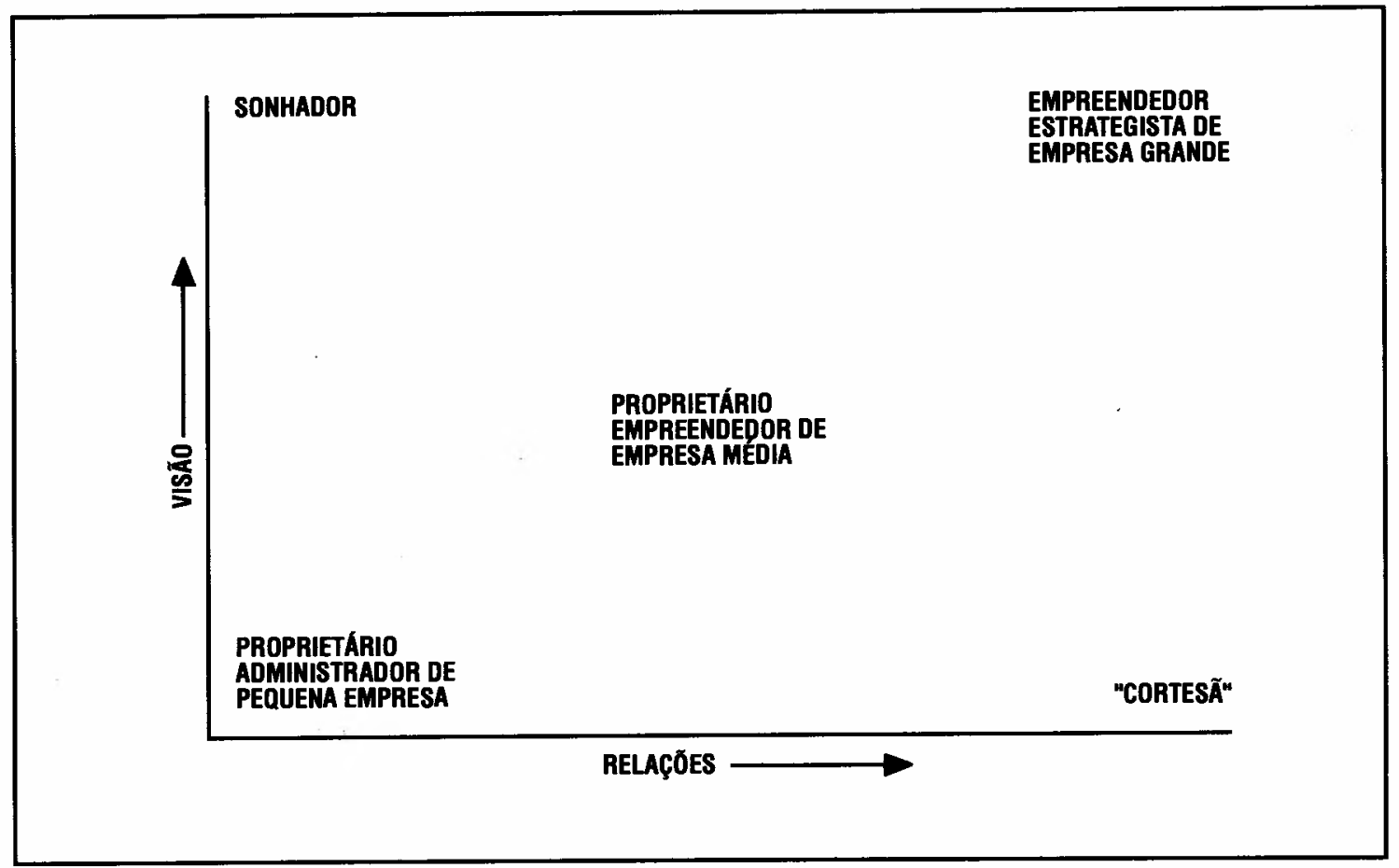

preendedor, em suas relações, aparecem no nível de cada subsistema. Essa estrutura tornase particularmente útil, se examinarmos as atividades do empreendedor segundo a sua visão, uma vez que ela nos leva a identificar a administração do sistema de relações como um elemento essencial para a evolução da visão. A figura 4 apresenta uma grade do empreendedor, que mostra a ligação entre visão e relações.

$O$ empreendedor que consegue adquirir uma visão clara e consistente, sem desenvolver simultaneamente um sistema de relações que o ajude a torná-lo uma realidade, corre o risco de permanecer como um mero sonhador ou, pelo menos, de não progredir muito rumo à sua visão. No outro extremo, encontra-se a "cortesã", pessoa que sabe de tudo, tem uma imensa rede de relacionamentos, mas não possui uma visão ou um sonho.

Tem que haver coerência entre a qualificação das pessoas que figuram no sistema de relações $\mathbf{e}$ as pretensões do empreendedor. Quanto mais ambiciosa for sua visão, tanto maior deverá ser a sua capacidade de atrair pessoas capazes. Na verdade, isto se torna indispensável, se ele pretender realizar, de fato, a visão. Pessoas há que desejam manter suas empresas num porte menor, enquanto outras desejam fazê-las crescer, assumindo porte médio ou grande. A partir dessa decisão é que elas efetuam a sua escolha de visão e, conseqüentemente, das relações. A forma pela qual essas duas variáveis se combinam explica como será a estratégia de empresa.

\section{AVALIAÇÃO dO SISTEMA DE RELAÇÕES}

O ponto crítico do desenvolvimento de visão é, sem dúvida, um bom gerenciamento do sistema de relações. O quadro 6 contém um exercício para esta finalidade.

\section{Quadro 6: Avaliaçăo do sistema de relaçōes - Exercício 2}

1. Descriçăo e avallaçăo dos sistemas de relaçöes primárias; secundárias e terciárias.

2. Ws e Relações.

3. Relaçöes e Ws.

4. Energia e relações.

5. Relaçōes e energia.

6. Relações e visão.

7. Visão e relações.

8. Relações e ação.

9. Ação e relaçōes.

10. Avaliação geral do sistema de relações. 
Quadro 7: Definindo contextos - Exercício 3

1. Descrição da visão (resumo).

2. Descrição do sistema de relações (resumo).

3. Avaliação da coerência entre 1 e 2.

4. Ações planejadas.

5. Plano para a definição de contextos e sistemas de relações.

6. Planejamento do seu próprio sistema de aprendizagem empresarial.

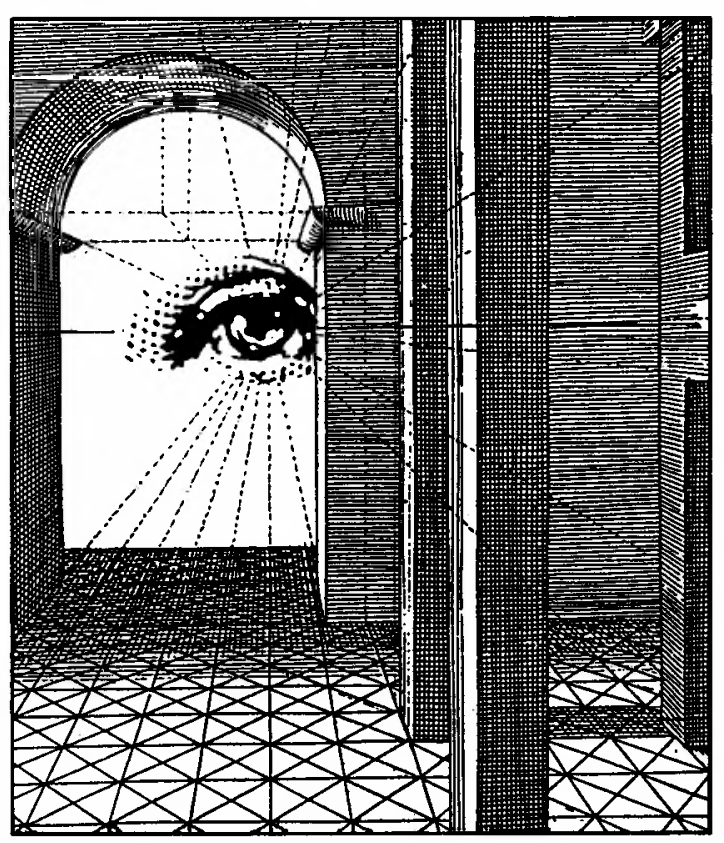

A finalidade desse exercício é alertar o empreendedor iniciante para os efeitos do seu sistema de relações sobre a evolução da sua visão. Ws são valores, formas pessoais de enxergar o mundo. $\mathrm{O}$ exercício consiste em descrever o sistema de relações, os efeitos recíprocos entre certos elementos, a começar dos que aparecem no metamodelo (figura 1), e as relações. Como exemplo, o estudante deverá analisar como as suas Ws ou valores levaram-no a selecionar as suas relações (passo 2) e, inversamente, como algumas dessas relações fizeram-no modificar as suas Ws (passo 3). Ele deverá perguntar a si mesmo quanta energia ele despende na criação e na preservação dos relacionamentos e, depois, quanta energia despendeu em cada relacionamento (passo 4). O nível de energia gerado em cada elemento do sistema é, então examinado. A parte restante do exercício deverá ser executada de modo idêntico, sempre tentando estabelecer os efeitos recíprocos entre os elementos.

Um exercício como esse pode tornar-se fascinante, porque o participante poderá descobrir fatores que o levaram a formular questões fundamentais, e até mesmo reconsiderar a forma de organizar a sua vida.

\section{Definindo Contextos}

O terceiro exercício, que está no quadro 7 , toma a forma de um plano de ação, no qual coisas a serem feitas, conhecimentos a serem adquiridos, relações a serem suspendidas ou desenvolvidas, necessidade de energia etc. deverão ser listadas.

Durante esse exercício, os participantes observarão a utilidade de trabalhar em cenários que, segundo a avaliação do seu atual sistema de relações, vão levá-los a desenhar um sistema ideal de relações, de acordo com a visão identificada.

Os três exercícios, em conjunto, deverão levar os participantes a refletirem sobre o seu progresso, de modo a entenderem a evolução de sua visão até aquele momento e a melhor se orientarem, pelo gerenciamento do contexto em que se encontram.

\section{CONCLUSÃO}

As atividades de treinamento têm que ser planejadas em consonância com $o$ assunto a ser tratado. É importante não confundir administradores com empreendedores. $\mathrm{O}$ empreendedor precisa identificar visões, antes que possa gerenciar recursos. Ele é proativo. Tal característica deve ser respeitada e usada no processo de treinamento, permitindo-lhe definir o seu próprio padrão de aprendizagem e, assim, reforçando a sua maneira de trabalhar. $\square$ 